\title{
Permanência na Educação Superior a distância
}

\section{Permanence in Distance Higher Education}

\author{
Pricila Kohls dos Santos \\ Lucia Maria Martins Giraffa \\ Pontifícia Universidade Católica do Rio Grande do Sul (Brasil)
}

\section{Resumo}

A temática da permanência estudantil na Educação Superior configura-se, ainda, como temática desafiadora, tanto na modalidade presencial como a distância. Este artigo apresenta os resultados de uma investigação sistematizados como sugestões de estratégias e ações para auxiliar a promoção da permanência. Usamos como referencial teórico o trabalho de Spady (1971), Pascarella (1985), Ethington (1990), Tinto (1997), García Aretio (2002), Tinto \& Pusser (2006) e Cabrera et al. (2006). A metodologia utilizada foi de caráter quali-quantitativo, tendo como objetivo verificar as variáveis de maior relevância para a permanência na Educação a Distância (EaD) às variáveis de maior relevância para a permanência na Educação a Distância (EaD) levando em consideração dois fatores: Dedicação do Estudante e Qualidade do Curso. Em geral, estudos encontrados na literatura enfocam a opinião de docentes e gestores em relação à evasão dos estudantes. Como diferencial esta investigação teve por objetivo dar voz ao discente e compreender o que faz ele/ela permanecer nos estudos. Os resultados da análise apontam que os indicadores considerados pelos estudantes, como mais relevantes para sua permanência são: cumprimento do programa acadêmico; técnicas e hábitos de estudo; atividades nas disciplinas e; promoção de discussões em fóruns e demais espaços de comunicação.

Palavras-chave: educação a distância; educação superior; evasão; permanência.

\begin{abstract}
The topic of student retention in higher education is challenging, in face-to-face as well as distance modalities. The pursuit of indicators and instruments that lead to an understanding of what makes students stay in education is a challenge. Using the work of Spady (1971), Pascarella (1985), Ethington (1990), Tinto (1997), García Aretio (2002), Tinto \& Pusser (2006) e Cabrera et al. (2006) as a theoretical foundation, a quasi-quantitative study was carried out to study the most relevant variables for retention in distance education. To that end, two factors were taken into consideration, namely: student dedication and program quality. As a result of this study, the indicators considered by the students to be the most relevant for their staying in the program were identified. This work aids the elaboration of projects and policies that contemplate aspects that help mitigate dropout in higher education, a serious problem with a high social cost.
\end{abstract}

Keywords: distance education; higher education; dropping out; dropouts; retention. 
Considerando os desafios da atual da sociedade globalizada e imersa neste contexto a educação superior a distância tem um papel importante no desenvolvimento social e das relações de trabalho, aprendizagem e ensino. Sendo a educação a distância $(\mathrm{EaD})$ uma modalidade de ensino que possibilita atender as necessidades de um número maior de pessoas. A evasão estudantil configura-se como um tema complexo e ao mesmo tempo imprescindível para a qualidade das ações de permanência dos estudantes na educação superior e para o desenvolvimento social brasileiro. Logo, faz-se mister conhecer os motivos pelos quais os estudantes abandonam seus estudos para, assim, projetar ações que auxiliem à permanência.

Neste sentido, o presente estudo visa estudar a temática do abandono a partir dos estudantes que permanecem, salientando que um dos aspectos que reforçam esta abordagem é a dificuldade de encontrar e contatar com os estudantes que não estão mais na instituição de ensino, uma vez que muitos deles mudam de endereço, telefone, correio eletrônico e o vínculo com a Instituição de Ensino Superior (IES) acaba se perdendo. Entendemos que ao dar voz ao estudante que permanece, podemos de uma forma indireta, identificar as possíveis causas que poderiam levar ao abandono dos estudos e, assim, antecipar ações que objetivem a não saída do discente.

\section{REFERENCIAL TEÓRICO}

No Brasil o sistema formal de Educação é regulamentado pelo Ministério da Educação (MEC). Este órgão federal é o responsável pela supervisão e acompanhamento das instituições de Educação no país, nas modalidades presenciais e a distância. A regulamentação da oferta na modalidade de Educação a Distância $(\mathrm{EaD})$ é recente se comparada a oferta presencial. Esta regulamentação tem sido objeto de atenção por parte dos órgãos reguladores em função da demanda cada vez mais crescente e, no início desordenada, dos cursos em EaD.

A fim de ampliar o acesso à educação superior ações e políticas públicas foram implementadas relacionadas à $\mathrm{EaD}$, especialmente àquelas concentradas no âmbito da Universidade Aberta do Brasil (UAB). A UAB é um consórcio de instituições públicas federais que ofertam de maneira conjunta formação superior em diversas áreas, tendo como foco a formação de professores. A UAB nasce como um vetor de aceleração para auxiliar na formação de docentes que já atuavam na rede pública e não possuíam graduação. O êxito desta estratégia fez com que se ampliasse o escopo de formação e, consequentemente, a oferta de diversos cursos tanto de graduação quanto de pós-graduação.

Com o crescimento da oferta EaD observa-se que a movimentação dos estudantes também se faz presente como no presencial. Num primeiro momento quando existe movimentação de estudantes com relação a seu vínculo com determinado curso e instituição, a leitura é que estamos tratando do fenômeno da evasão. Ristoff (1999) 
afirma que em muitos casos o que é chamado de evasão é mobilidade acadêmica, que não deve ser encarado como fracasso e sim, como tentativa em busca de sucesso.

Estudos realizados por autores de diferentes países, tais como: Spady, (1971), Tinto (1997), Pascarella (1985), Cabrera at all (2006), Ethington (1990), dentre outros, mostram que o tema é complexo e com múltiplas facetas de análise e definição.

Vincent Tinto, pesquisador norte-americano, apresentou em 1989 um estudo que viria a mudar o entendimento desse fenômeno. Para o autor são comportamentos diversos que levam a exclusão acadêmica e o abandono voluntário. Para um observador externo o fato de um estudante abandonar seu curso pode ser entendido como fracasso, porém, esse mesmo estudante, pode interpretar essa situação como algo positivo visto que sua meta pessoal não seria atingida se permanecesse naquele curso. Logo, trocar de curso, cancelar a opção feita, pode não denotar fracasso e sim amadurecimento em função da experiência vivida naquele curso. Quantos estudantes só entendem efetivamente o curso em que se matricularam apenas quando o vivenciam?

Trocar de curso, cancelar um curso, cancelar sua matrícula na instituição pode ter múltiplas causas. Restringir este complexo cenário a interpretação reducionista de fracasso escolar é desconsiderar a mobilidade, contextos econômicos difíceis, situações pessoais e outras. Tinto (1997) afirma que as interpretações são diferentes porque a meta e interesse entre o discente e o observador são diferentes.

De acordo com a literatura, alguns enfoques e perspectivas podem ser distinguidos quando da investigação relacionada ao abandono, podendo destacar os enfoques psicológicos, sociológicos, econômicos, organizacionais e interacionista. O enfoque psicológico tem como um dos autores, Ethington (1990), o qual sinaliza que o abandono é um possível resultado de uma falta de clareza com relação às intenções iniciais do estudante e que sua vida anterior, assim como seus estudos prévios, ao ingresso na Educação Superior difere entre os discentes que abandonam e dos que permanecem.

A abordagem sociológica leva em consideração a integração acadêmica como determinante para o abandono. O modelo interacionista, de Tinto (1997), concentrase na esfera institucional como ponto chave para o desencadeamento da opção pelo abandono. Sendo que Cabrera et al. (2006) destacam que os estudantes permanecem quando percebem o benefício social e econômico atrelado aos estudos. Ainda ressaltam que as condições financeiras têm reflexo positivo não só para o ingresso do estudante, mas também para participar de atividades acadêmicas e sociais extraclasse na instituição e fora desta.

No que tange a Educação a Distância, Martinez (2003, p. 3) afirma que:

Evasão (Dropout) ocorre quando o estudante abandona o curso ou o sistema de educação durante o seu desenvolvimento e nunca retorna. Já o trancamento (stopout) é a interrupção temporária do curso, e evasão do curso (atteainer) ocorre quando o estudante sai do curso antes da sua conclusão, mas com a aquisição do conhecimento, 
ou por ter atingido suas metas pessoais. Já o caso dos estudantes que nem chegam a iniciar o curso é chamado de non-starter (não iniciante).

Para García Aretio (2002), é necessário distinguir, no caso da EaD, entre o abandono real (quando o aluno já frequenta o curso) e o abandono sem iniciar o curso. Entende-se por abandono sem iniciar um curso, quando o estudante realiza matrícula, mas não há registro de nenhuma atuação no mesmo, geralmente usase como indicador as avaliações. Ou seja, o estudante frequenta o curso, mas não realiza nenhuma tarefa avaliativa que lhe conferiria os créditos de uma disciplina. $\mathrm{O}$ abandono real é aquele em que o estudante realiza alguma avaliação, mas não todas necessárias para finalização do curso.

Tinto (2012) apresenta um modelo para a permanência, do qual podemos destacar cinco fatores principais. A expectativa: quando os estudantes esperam ser bem-sucedidos a partir do curso, eles estão mais propensos à permanência. $\mathrm{O}$ aconselhamento: quanto maior a informação dada pela instituição acerca dos seus programas de estudo, mais seguro o estudante sente-se para permanecer. Além disso, tem maiores chances de permanecer os estudantes que têm a oportunidade de receber apoio pessoal e social na instituição, principalmente para estudantes no primeiro ano de ingresso na Universidade. A participação diz respeito ao envolvimento acadêmico e interação, quer seja com os professores, colegas de curso ou demais agentes do contexto educacional ao qual está inserido, ao passo que, se esse envolvimento é efetivo, maior é a chance da permanência. A aprendizagem, que tem interferência direta para a permanência, mas também influenciam as intenções para com os estudos e o compromisso com a instituição, que, por sua vez, também tem influência na permanência. Estes dois últimos aspectos são enfatizados por Moncada Mora (2014) e Moreno Almazán (2015) que ressaltam a importância da integração dos estudantes e do bom planejamento de atividades como fatores que auxiliam a permanência em cursos na modalidade a distância.

\section{PROCEDIMENTOS METODOLÓGICOS}

Esta investigação utilizou abordagem mista (qualitativa e quantitativa). A pesquisa de natureza qualitativa permite aos pesquisadores conhecerem variáveis não contempladas pelo método quantitativo, como neste caso onde buscamos elementos para compreender a decisão do estudante de abandonar a universidade, a percepção do estudante com relação às IES e seus cursos de graduação a distância. A investigação foi realizada levando em consideração duas etapas: a pesquisa bibliográfica e a pesquisa de campo.

Uma vez concluída a pesquisa bibliográfica, foi realizada a pesquisa de campo, objetivando coletar informações e/ou conhecimentos acerca de um problema (Lakatos \& Marconi, 2014). O instrumento utilizado para coleta de dados foi um questionário, que "é um instrumento de coleta de dados, constituído por uma série 
ordenada de perguntas, que devem ser respondidas por escrito e sem a presença do investigador" (Lakatos \& Marconi, 2014, p. 88).

A abordagem mista permite a complementariedade da pesquisa qualitativa para a pesquisa quantitativa e vice-versa. Para tal foi utilizado o método de triangulação dos dados, sugerido por Flick (2013). O autor afirma que ambas as abordagens dão sustentação uma à outra e podem apresentar um quadro mais geral da problemática estudada. Essa abordagem é empregada com o intuito de ampliar as possibilidades de dados oriundos dos instrumentos propostos para essa investigação. Observando estas diretivas foi aplicado o questionário com estudantes da Educação Superior a Distância, sendo que tal instrumento passou por etapas de validação, sendo avaliado por especialistas da área de Educação e de EaD e pré-testado com 12 estudantes que não fizeram parte da amostra utilizada na análise dos dados. O questionário, com questões abertas e fechadas, foi aplicado por meio eletrônico, destacando que para participar da pesquisa fez-se imprescindível expressar concordância com o Termo de Consentimento Livre e Esclarecido apresentado no início do instrumento online.

Para análise dos resultados relacionados às questões abertas foram seguidas as etapas de análise de conteúdo propostas por Bardin (2012), que são: a pré-análise, a exploração do material e a análise e interpretação dos resultados, com o intuito de levantar e identificar as estratégias desenvolvidas pelos sujeitos e sua trajetória na realização do curso. O levantamento dos dados se deu a partir das leituras, tanto dos trabalhos já realizados, quanto do questionário direcionado aos estudantes. Já os dados quantitativos foram analisados com o auxílio do pacote estatístico, Statistical Package for Social Science (SPSS), que permite a utilização técnicas de análise estatística descritiva e estatística multivariada.

O instrumento de coleta de dados destinado a estudantes da Educação Superior a distância, levou em consideração informações sobre o contexto Institucional, Condições pessoais, Condições Socioacadêmicas e Condições socioeconômicas, outrossim consideramos questões relacionadas à gestão da instituição, qualidade do curso, dedicação do estudante e a prática docente.

\section{Modelo de análise}

Da problematização advinda do levantamento bibliográfico, estabelecemos o modelo analítico contendo as informações levantadas nos contornos do estudo construído. Um modelo analítico deve ser construído para representar um sistema ou processo real, fazendo uso de variáveis e seus inter-relacionamentos, permitindo a composição de variáveis, dependentes ou independentes, possibilitando o estabelecimento de hipóteses de estudo, que são afirmações ou proposições a respeito de um fator ou fenômeno (Malhotra, 2012).

Nesse sentido, para análise quantitativa dos dados obtidos propusemos um Modelo de Predição, fazendo uso de estatística multivariada, considerando, para tal, o levantamento e estudo da literatura especializada no tema. Utilizamos como 
referência os trabalhos de Tinto (1997, 2012), Tinto e Pusser (2006), Cabrera et al. (1992), Cabrera et al. (2006), Himmel (2002), Moore e Kearsley (2012), Litto e Formiga (2012), Palloff e Pratt (2004) a fim de identificar fatores principais no intuito de explicar a permanência e/ou abandono estudantil na Educação Superior a Distância.

A partir dos estudos realizados, elencamos quatro fatores que podem contribuir para a permanência de estudantes em cursos de graduação. Os fatores identificados são: Gestão Institucional, Prática Docente, Qualidade do Curso e Dedicação do Estudante. Acreditamos que cada um dos fatores denominados possui relação direta com a permanência, sendo que acreditamos existir, também, uma relação indireta com a permanência quando relacionados os fatores entre si. Neste artigo, tomamos como foco principal os fatores associados à Qualidade do Curso e Dedicação do Estudante para os quais foram estabelecidas as seguintes hipóteses:

- Hipótese $\mathrm{H}_{1}$ : quanto maior a dedicação do estudante, maior a probabilidade de $\mathrm{o}$ mesmo permanecer nos estudos.

- Hipótese $\mathrm{H}_{2}$ : quanto melhor a qualidade do curso, maior a probabilidade de o estudante permanecer nos estudos.

Reiteramos que o objeto deste trabalho é conhecer os motivos pelos quais os estudantes da EaD permanecem em seus estudos.

Procedimento de Análise dos dados quantitativos

A análise quantitativa dos dados foi realizada, num primeiro momento, usando a análise estatística descritiva, por meio das frequências e percentuais das variáveis relacionadas às características pessoais, socioeconômicas e aspectos acadêmicos. Frequências entre idade e gênero, formação antes de ingressar na Educação Superior e categoria administrativa da IES e de Ensino Médio foram comparadas quando a correlação de Spearman apresentando significância com valores menos que 0,05, ou seja, $\mathrm{p}<0,05$.

Para o teste das hipóteses desta investigação foram utilizadas as técnicas de análise de regressão, teste de validação de construto, análise fatorial e análise de correlações. De acordo com Malhotra (2012) a análise de correlações é empregada para resumir a intensidade de associação entre duas variáveis métricas. Já a análise de regressão permite analisar as associações entre uma variável dependente e uma ou mais independentes, sendo que o objetivo dessa análise é verificar a natureza e o grau de associação entre as variáveis, podendo se utilizar para determinar se existe relação e determinar a intensidade dessa relação. 


\section{Sujeitos da pesquisa}

Inicialmente foram contatadas instituições que possuem cursos a distância a fim de viabilizar a coleta de dados, foi nesse momento que os entraves aconteceram em função da natureza da investigação. Isto é, as instituições sentiram-se desconfortáveis em fornecer seus dados relacionados à evasão. Podemos citar, dentre outras dificuldades, motivos de ordem temporal, dificuldade de contato com a gestão da instituição, mas principalmente os aspectos relacionados ao cenário competitivo do mercado de EaD no Brasil. Um fato que corrobora com este cenário é o grande número de investidores estrangeiros nesse nicho de mercado, sendo que uma das IES contatadas relatou que, embora tivesse um grande interesse em realizar a pesquisa, negociações financeiras relativas ao grupo investidor impediam a viabilização da mesma. Uma vez que a temática da permanência e do abandono estudantil, por vezes, denotaria insucesso por parte das instituições na oferta de $\mathrm{EaD}$ e isto acarretaria menor valor de venda da empresa ao grupo consolidador.

Contudo, o universo no qual foi desenvolvida essa investigação é composto por estudantes de Graduação a Distância ingressantes nos anos de 2011 a 2015, que estão matriculados ou abandonaram seus estudos antes de concluí-los. Para compor a amostra foram contatados 333 estudantes de um polo de $\mathrm{EaD}$ da região metropolitana de Porto Alegre (RS), sendo a participação realizada por meio de convite, via e-mail.

Neste sentido, compuseram a amostra estudantes dos cursos de Pedagogia, Administração de Empresas, Ciências Contábeis, Gestão Pública, Administração Hospitalar, Análise e Desenvolvimento de Sistemas, Gestão de Recursos Humanos, Gestão Financeira, História, Matemática, Processos Gerenciais e Serviço Social. Salientamos que, para manter o sigilo da instituição investigada, optamos por caracterizar a IES apenas de maneira geral, pois, em função das especificidades existentes em cada instituição que oferta $\mathrm{EaD}$, a mesma poderia ser identificada pela metodologia adotada ou suas características. Assim, o número de participantes atingiu 126 estudantes e deste número foram validados 86 questionários, os demais foram invalidados por apresentarem inconsistências, tais como: itens sem resposta e informações insuficientes para o estudo.

\section{ANÁLISE DOS DADOS}

A partir da análise estatística descritiva percebemos que, referente à idade, os estudantes pesquisados têm, em média, 33 anos, sendo 19 anos a menor idade registrada e o maior percentual de concentração da idade em estudantes com mais de 35 anos (44\%). Com relação ao gênero, 90,6\% dos participantes da pesquisa são do sexo feminino e $9,4 \%$ masculino.

Em relação ao contexto familiar, observamos que 4,7\% dos pais não são alfabetizados e que o maior percentual de escolaridade corresponde ao Ensino 
Fundamental, com 54,7\%, sendo que 15,1\% não possui escolaridade formal, porém é alfabetizado, assim como 9,3\% têm o Ensino Médio, 5,8\% dispõem formação técnica e apenas $7 \%$ dos pais possui graduação. Portanto, $64 \%$ dos pais incluem-se no âmbito da Educação Básica e 19,8\% destes não fez parte do sistema formal de educação.

A mesma tendência pode ser observada quanto à escolaridade da mãe, dentre as quais foi constatada à presença, mesmo que pequena, de estudos de pós-graduação (dois casos) e com relação ao pai não há nenhum caso presente. A maior incidência com relação à escolaridade da mãe está no Ensino Fundamental com 52,3\% dos respondentes, seguido de alfabetizado sem escolaridade formal (16,3\%). As mães com Ensino Médio somam 9,3\%, 7\% possui Ensino Técnico e 3,5\% delas não são alfabetizadas. Em nível de Educação Básica é 61,6\%, praticamente o mesmo valor com relação aos pais, sendo que alguma diferença é evidenciada, para a escolaridade, na Educação Superior, na qual 11,6\% das mães possuem formação em relação a 7\% dos pais. Ainda sobre o contexto familiar, ao responderem à questão dos hábitos de estudo, $87 \%$ dos estudantes responderam que a família os promovem e os facilitam, apenas $13 \%$ dos estudantes posicionaram-se contrários a esta afirmação. Já referente ao contexto socioeconômico, $74,4 \%$ dos discentes afirmam dependerem financeiramente apenas de si mesmos, $19,8 \%$ de cônjuge ou companheiro(a) e apenas 5,8\% declararam depender financeiramente dos pais.

Na questão vinculada a alguma experiência que alterasse seu modo e hábitos de vida durante o último ano de permanência no curso (salientamos que esta questão é de respostas múltiplas), do total de estudantes 10,5\% afirmaram ter passado por mudança de estado civil, 8,1\% tornaram-se pai ou mãe, $12,9 \%$ declararam haver passado por problemas de caráter psíquico, $2,3 \%$ ingressaram no campo laboral, $16,3 \%$ sofreram desemprego pessoal e 8,1\% passaram por desemprego no núcleo familiar, outros eventos não mencionados somam 22,1\% e 45,3\% dos estudantes declararam não ter passado por nenhuma experiência dessa natureza. Tais números reforçam a ideia de que o estudante de Educação a Distância tem o foco na conclusão do curso, pois mesmo passando por alguma experiência estressante mantêm-se com o foco na conclusão dos estudos, ou seja, permanece, pois sabe que disso depende a melhoria de suas condições socioeconômicas. (Ristoff, 2012).

Com relação à trajetória de estudos, os respondentes foram questionados acerca dos cursos anteriores ao ingresso na Educação Superior. De tal modo, 74,4\% dos estudantes são oriundos do Ensino Médio realizado em escola pública, 23,3\% afirmam terem frequentado escola particular e 2,3\% assinalaram a opção outro, o que correspondeu a dois estudantes que concluíram seus estudos em escola da rede particular, porém com bolsa de estudos. Outro aspecto que nos parece importante considerar é o motivo pela escolha do curso de graduação e a modalidade a distância. Neste sentido, para $62,9 \%$ dos estudantes a razão pela escolha do curso é por ter vocação para o mesmo, 29,1\% escolheram seu curso por acreditar que há facilidade de colocação no mercado de trabalho, $7 \%$ realizaram sua escolha em função de tradição familiar, $26 \%$ por orientação profissional e $20,9 \%$ por outros motivos. Dos quais 
podemos citar: exigência para concurso, estudante já atua na área do curso, plano de carreira e desejo de melhorar a educação. Ressaltamos que para esta questão o respondente poderia selecionar mais de uma opção, ou seja, é uma questão de respostas múltiplas. Mesmo caso da questão sobre a escolha da modalidade.

No que tange às razões da escolha da modalidade, $65 \%$ dos estudantes optaram pela modalidade a distância pelo baixo custo atrelado a esta, $49 \%$ pela facilidade de acesso, $54 \%$ elegeram a EaD por falta de tempo para assistir aulas presenciais na instituição, $7 \%$ escolheram um curso a distância porque gostam de tecnologia e 6\% alegam outros motivos, tais como: autonomia para o estudo, em função de filho pequeno e também por cursar outra graduação presencial.

Com relação às atividades do curso, $18,6 \%$ dos discentes afirmaram que as atividades são realizadas com aula presencial+atividades a distância+prova presencial. 70,9\% dos estudantes declararam que compõem atividades do curso aula presencial+AVA+prova presencial e 10,5\% dos estudantes alegaram haver somente AVA+prova presencial. Ou seja, majoritariamente as atividades dos cursos são compostas por encontro presencial, prova presencial e atividade a distância, que pode ser realizada em AVA ou por outro meio.

De acordo com os estudantes, sua dedicação aos estudos em número de horas, excetuando encontro presencial, é de mais de vinte horas para $8,2 \%$ dos estudantes, vinte horas para $10,5 \%$, dez horas para $34,9 \%$, de duas a cinco horas para $39,5 \% \mathrm{e}$ duas horas para $7 \%$.

As respostas à questão da interação a distância dos estudantes demonstram que, pelo menos, $89,4 \%$ interage com algum membro relacionado ao curso em que está matriculado, apenas 10,6\% dos estudantes não interagem com ninguém a distância, somente no polo de apoio presencial. Dos que interagem com o professor são 37,6\%, com o tutor $49,4 \%$, com os colegas $80 \%$ e outros $2,4 \%$. Destacamos que um estudante pode interagir com participantes com diferentes papéis no curso.

Após apresentação das variáveis por meio da estatística descritiva, realizamos a análise por meio da estatística multivariada das variáveis: Dedicação do Estudante e Qualidade do Curso.

Estas variáveis são compostas por um bloco de questões que se relacionam por meio de uma variável dependente. Tais variáveis foram construídas a partir da escala tipo Likert. Para tal, foi utilizada a média via pontuação atribuída às respostas, na qual 1 equivale a discordo totalmente e 5 a concordo totalmente. Assim, são considerados concordantes os que apresentam valores maiores que 3, discordantes os valores menores que 3 e neutro (nem concorda, nem discorda) valores exatamente 3. Para as escalas tipo Likert a pontuação segue a mesma atribuição, na qual 1 equivale a muito ruim e muito insatisfeito e 5 equivale a muito bom e muito satisfeito.

Para a variável Dedicação aos estudos foi utilizada a escola tipo Likert, que vai de muito ruim a muito boa. A mesma classificação de média foi empregada a essa questão, sendo seus valores apresentados na tabela 1, os quais indicam que, pela média, o sentimento dos respondentes com relação a sua formação anterior é bom; o 
cumprimento do programa acadêmico (dedicação nas atividades, tarefas,...) tende de bom a muito bom; que consideram bom seu tempo dedicado aos estudos; consideram que possuem boas técnicas de estudos; seu aprofundamento com leituras também é bom assim como a realização de práticas e estágios curriculares; sua participação em atividades extracurriculares (seminários, semana acadêmica, congressos, etc.) também é boa e a maioria dos estudantes considera boa sua dedicação aos estudos.

Tabela 1. Dedicação aos estudos

\begin{tabular}{|l|c|c|}
\hline & Media & Desvio padrão \\
\hline Formação antes de ingressar na instituição & 3.72 & 0.94 \\
\hline Cumprimento do programa academic & 4.08 & 0.72 \\
\hline Tempo dedicado ao estudo & 3.69 & 0.81 \\
\hline Técnicas e hábitos de estudo & 3.66 & 0.71 \\
\hline Aprofundamentos de leituras & 3.55 & 0.80 \\
\hline $\begin{array}{l}\text { Realização de práticas/estágios } \\
\text { extracurriculares }\end{array}$ & 3.85 & 0.97 \\
\hline Participação em atividades extraclasse & 3.43 & 0.94 \\
\hline Considero minha dedicação aos estudos & 3.99 & 0.78 \\
\hline
\end{tabular}

Com relação à qualidade do curso, os estudantes concordam que as atividades nas disciplinas atendem suas necessidades de formação, também estão de acordo que os conteúdos trabalhados estão dimensionados com o período de cada disciplina. Consentem que os conteúdos trabalhados abordam temas e tendências atuais e contribuem para a inserção no mercado de trabalho, aquiescem que a exposição dos temas foi realizada de forma clara e acessível, que a utilização de elementos multimídia auxilia a entender os conteúdos trabalhados e a realizar as tarefas propostas, que as atividades que foram propostas, como exercícios e prática, auxiliaram na aprendizagem dos conteúdos. Também assentem que a quantidade de atividades esteve em número adequado e o tempo para realização das mesmas foi suficiente, ainda subscrevem que a promoção de discussões durante as disciplinas resulta positivamente para a aprendizagem e concordam que o nível da qualidade do curso é excelente. Porém alguns estudantes trazem a necessidade de atividades mais práticas ao longo do curso, como salientado pelo Estudante 12 "apenas sinto falta durante as aulas presenciais de atividades práticas como meu curso é pedagogia acredito que poderíamos ter feito um trabalho melhor se tivéssemos mais práticas".

Apartir dos valores de média e desvio padrão das variáveis: "dedicação aos estudos" e "qualidade do curso" foram realizados testes de confiabilidade e consistência interna calculado o valor de Alfa de Cronbach. O coeficiente de confiabilidade Alfa de Cronbach é medido numa escala de o a 1, sendo o valor mínimo aceitável o,6 para 
se considerar um fator confiável (HAIR et al., 2013). As medidas de consistência interna do Fator 1 - Qualidade do curso resultou em 0,890 e o Fator 2 - Dedicação do estudante resultou em 0,955 . Por apresentar valores acima de 0,8 , ou seja, o conjunto de itens está funcionando de maneira precisa, pode-se concluir que ele mede aquilo a que se propõe de maneira consistente.

Ao verificarmos que as variáveis possuíam consistência interna pudemos afirmar que os itens que compõem a variável (fator) respondem de maneira confiável a variável proposta. Assim, foi aplicada a estes dados a técnica de regressão múltipla, trata-se de uma técnica estatística multivariada utilizada para analisar a relação entre uma única variável dependente e diversas variáveis independentes (HAIR et al., 2013). Cabe ressaltar que esta técnica pode ser empregada quando há uma variável dependente vinculada a outras independentes, sendo importante salientar que quanto maior for o valor de R2, melhor se explica a variação nos dados. E o valor do Beta $(\beta)$ padronizado que indica as contribuições relativas das variáveis para a predição.

A tabela 2 apresenta a análise de regressão das variáveis que compõe o fator Dedicação do Estudante, sendo a variável dependente a questão "Considerando os aspectos anteriores, considero minha dedicação aos estudos...”.

Tabela 2. Análise de Regressão Com relação à Dedicação do estudante

\begin{tabular}{|l|c|c|c|c|c|}
\hline $\begin{array}{c}\text { Com relação aos seus estudos, avalie sua } \\
\text { dedicação nos seguintes aspectos de sua } \\
\text { formação }\end{array}$ & $\beta$ & $\begin{array}{c}\text { Std. } \\
\text { Error }\end{array}$ & $\beta$ padr. & $\mathrm{t}$ & $\begin{array}{c}\text { Sig. } \\
\text { Valor p }\end{array}$ \\
\hline Formação antes de ingressar na instituição & 0,029 & 0,065 & 0,033 & 0,449 & 0,654 \\
\hline Cumprimento do programa acadêmico & 0,258 & 0,1 & $\mathbf{0 , 2 3 5}$ & 2,589 & $\mathbf{0 , 0 1 2}$ \\
\hline Tempo dedicado ao estudo & 0,149 & 0,1 & 0,156 & 1,489 & 0,141 \\
\hline Técnicas e hábitos de estudo & 0,391 & 0,128 & $\mathbf{0 , 3 5 7}$ & 3,064 & $\mathbf{0 , 0 0 3}$ \\
\hline Aprofundamentos de leituras & 0,066 & 0,096 & 0,068 & 0,688 & 0,493 \\
\hline $\begin{array}{l}\text { Realização de práticas/estágios } \\
\text { extracurriculares }\end{array}$ & 0,087 & 0,068 & 0,108 & 1,276 & 0,206 \\
\hline Participação em atividades extraclasse & 0,086 & 0,063 & 0,103 & 1,359 & 0,178 \\
\hline
\end{tabular}

$$
R^{2} \text { da Regressão }=69 \%
$$

Obs.: Resultados da análise de regressão tomando como variável dependente a questão G.29.8, considerando os aspectos anteriores, considero minha dedicação aos estudos...” $e$ as demais questões do bloco como independentes.

Observa-se que na tabela 2, pelo valor de R2 que 69\% das variações em Y (dependente) podem ser explicadas pelo conjunto de variáveis do bloco, com um valor de significância $\mathrm{p}<0,05$. Sendo as variáveis: Cumprimento do programa acadêmico e técnicas e hábitos de estudo, as que mais impactam na variável dependente, ou seja, 
estes são os aspectos mais relevantes, no âmbito deste estudo, para a Dedicação do Estudante. Os hábitos e técnicas de estudo em grande parte determinam o sucesso em cursos a distância, outrossim, os discentes que não conseguem cumprir o programa acadêmico a tempo, tendem a desistir dos estudos (Moore \& Kearsley, 2012).

Nesse sentido, podemos afirmar que os estudantes com melhores hábitos de estudos e que procuram cumprir os prazos tendem a ter uma melhor percepção acerca da sua dedicação aos estudos. Sendo que em EaD é imprescindível conscientizar o estudante e aconselhá-lo na experiência do aprendizado a distância, o qual vai requer, além da dedicação, disciplina para o cumprimento das atividades e estabelecimento de metas de aprendizagem; hábitos, aos quais, os discentes, costumam não estar familiarizados a organizar e, até mesmo considerar como suas responsabilidades. Na educação presencial muitas destas questões estão "resolvidas" pela cobrança do professor e o cronograma de atividades presenciais que, de certo modo, pressiona o estudante a ter um ritmo. $\mathrm{Na} \mathrm{EaD} \mathrm{ele/ela} \mathrm{está} \mathrm{livre} \mathrm{para} \mathrm{compor} \mathrm{seu} \mathrm{ritmo,} \mathrm{o} \mathrm{que}$ pode ser uma fragilidade se não for bem administrado.

Com relação à Qualidade do curso, foi considerado como variável dependente para a análise de regressão a questão (Considerando os aspectos anteriores, considero o nível de qualidade do meu curso excelente.), sendo as questões apresentadas na tabela 3 tratadas como variáveis independentes.

Tabela 3. Análise de Regressão Com relação à Qualidade do curso

\begin{tabular}{|l|c|c|c|c|c|}
\hline \multicolumn{1}{|c|}{$\begin{array}{c}\text { Indica seu grau de concordância com relação à } \\
\text { qualidade do curso }\end{array}$} & $\beta$ & $\begin{array}{c}\text { Std. } \\
\text { Error }\end{array}$ & $\beta$ padr. & t & $\begin{array}{c}\text { Sig. } \\
\text { Valor p }\end{array}$ \\
\hline $\begin{array}{l}\text { As atividades nas disciplinas atendem minhas } \\
\text { necessidades de formação }\end{array}$ & 0,231 & 0,111 & $\mathbf{0 , 2 1 5}$ & $\mathbf{2 , 0 8 2}$ & $\mathbf{0 , 0 4 1}$ \\
\hline $\begin{array}{l}\text { Os conteúdos trabalhados estão dimensionados } \\
\text { em concordância com o período de cada disciplina }\end{array}$ & 0,159 & 0,098 & 0,157 & 1,619 & 0,11 \\
\hline $\begin{array}{l}\text { Os conteúdos trabalhados nas disciplinas } \\
\text { consideram temas } \text { e tendências atuais } \text { e } \\
\text { contribuem para sua inserção futura no mercado } \\
\text { de trabalho }\end{array}$ & 0,133 & 0,106 & 0,14 & 1,248 & 0,216 \\
\hline $\begin{array}{l}\text { A exposição dos temas foi realizada de forma } \\
\text { clara e acessível }\end{array}$ & 0,161 & 0,101 & 0,175 & 1,599 & 0,114 \\
\hline $\begin{array}{l}\text { A utilização de elementos multimídias me auxiliou } \\
\text { a entender os conteúdos trabalhados e a realizar } \\
\text { as tarefas propostas }\end{array}$ & 0,095 & 0,077 & 0,124 & 1,234 & 0,221 \\
\hline $\begin{array}{l}\text { As atividades propostas me auxiliaram na } \\
\text { aprendizagem dos conteúdos }\end{array}$ & 0,089 & 0,11 & 0,092 & 0,812 & 0,419 \\
\hline $\begin{array}{l}\text { O tempo disponibilizado para realização das } \\
\text { atividades foi suficiente }\end{array}$ & 0,016 & 0,112 & 0,016 & 0,139 & 0,89 \\
\hline
\end{tabular}




\begin{tabular}{|l|c|c|c|c|c|}
\hline $\begin{array}{c}\text { Indica seu grau de concordância com relação à } \\
\text { qualidade do curso }\end{array}$ & $\beta$ & $\begin{array}{c}\text { Std. } \\
\text { Error }\end{array}$ & $\beta$ padr. & $t$ & $\begin{array}{c}\text { Sig. } \\
\text { Valor p }\end{array}$ \\
\hline $\begin{array}{l}\text { A promoção de discussões resultou positivamente } \\
\text { para sua aprendizagem }\end{array}$ & 0,226 & 0,082 & $\mathbf{0 , 2 3 9}$ & $\mathbf{2 , 7 3 7}$ & $\mathbf{0 , 0 0 8}$ \\
\hline
\end{tabular}

$R^{2}$ da Regressão $=63 \%$

Obs.: Resultados da análise de regressão tomando como variável dependente a questão G.30.10, considerando os aspectos anteriores, considero o nível de qualidade do meu curso excelente e as demais questões do bloco como independentes.

O bloco Qualidade do curso pode ser explicado por 63\% das variações da variável dependente pelo conjunto das variáveis do bloco. Identificamos as variáveis "atividades que atendem as necessidades de formação" e "promoção de discussões resulta positivamente para aprendizagem", considerando o nível de significância $\mathrm{p}<0,05$, como as variáveis de maior impacto no bloco, ou seja, para a qualidade do curso ser considerada excelente. De acordo com Moore e Kearsley (2012) e García Aretio (2014) a qualidade em EaD passa por aspectos como: a organização do curso, os conteúdos, a docência e os sistemas de apoio. Nesse sentido corrobora com os estudantes pesquisados que apresentam como mais impactante para a qualidade do curso as discussões e as atividades realizadas, sendo estas resultantes de conteúdo e docência, pois ao falar em promoção de discussões para aprendizagem e realização de atividades para a formação, não se pode excluir esses dois aspectos, pois o cerne donde são desenvolvidas essas ações é a educação.

$\mathrm{Na}$ sequência, realizamos a análise regressão para verificar o impacto das variáveis dentro de cada bloco, ou seja, se as questões estão relacionadas entre si. Essa análise se deu no intuito de medir as variáveis que mais influenciam a questão geral de cada bloco. Com o objetivo de verificar se os fatores analisados apresentam impacto direto com a permanência, para tal foi realizada a análise de regressão entre a Qualidade do Curso e a Permanência e também a Dedicação do Estudante e a Permanência.

Com relação à Qualidade do curso, efetuamos a análise de regressão tomando como variável dependente a "qualidade do curso me motivou a permanecer nos estudos”. Desta análise resultou um valor de $\mathrm{R} 2=0,521$, isto é, $52 \%$ da variação da variável dependente pode ser explicada pelas questões do bloco.

A partir dos achados foi possível verificar que são quatro as variáveis com maior impacto, a saber: as atividades nas disciplinas, a utilização de elementos multimídia, a quantidade de atividades em número adequado, a promoção de discussões. Essas quatro variáveis explicam os aspectos que os estudantes observam ao levar em consideração a qualidade do curso para a permanência nos estudos, sendo que a promoção de discussões é o aspecto de maior impacto nessa relação.

Com relação à dedicação, ao analisar o bloco de questões acerca da Dedicação do estudante com a permanência, obtivemos um valor de R2=0,256, o que explica que 
25\% das variações da variável dependente "Dedicação aos estudos acadêmicos" podem ser explicadas pelas variáveis do bloco. Da relação entre a dedicação do estudante e permanência, percebemos que a variável de maior impacto é o aprofundamento de leituras. Esse é um aspecto que chama a atenção no sentido de o estudante perceber essa influência, mesmo que subjetivamente. Na Universidade como um todo, cada vez mais é exigido e esperado do discente que o mesmo tenha autonomia e proatividade frente aos seus estudos. Principalmente na EaD é necessário que o estudante tenha esse posicionamento de constante busca pelo aprender, além de ter disciplina para realização das atividades.

Complementar a esses dados, destacamos o posicionamento de um respondente ao apontar como positivo "ter autonomia nos horários para estudo e a oportunidade de aprofundar no mundo da leitura e aprendizagem por conta própria" (Estudante 22).

A EaD prescinde da presença física dos estudantes, mas não prescinde da dedicação e do aprofundamento de leituras e conhecimento exigidos pela sociedade e, por conseguinte, pela vida acadêmica, sendo que, em alguns casos, o aprofundamento de leituras pode ser interpretado como uma opção a aula expositiva do presencial.

$\mathrm{O}$ estudante de $\mathrm{EaD}$, de acordo com a amostra, parece ser consciente deste seu papel, porém o baixo valor de R2 pode denotar a dificuldade de o estudante olhar para si mesmo e avaliar sua responsabilidade para com o processo de aprendizagem, dificuldade esta inerente da humana condição. Porém, um dos discentes declara que: "Posso aprender estudando e se eu não estudar vou reprovar em qualquer faculdade" (Estudante 51). O estudante percebe a importância de se dedicar aos estudos, independente da modalidade escolhida para realizar seus estudos.

Embora não tenha apresentado resultados tão significativos quanto aos demais fatores da análise fatorial, é de conhecimento que a dedicação do estudante é condição imprescindível para a realização de um curso a distância. Como mencionado na análise estatística dos dados, os hábitos de estudo e a organização para o acompanhamento do curso e a realização das atividades são um dos elementos fundamentais para o sucesso nos estudos a distância.

Nesse sentido um respondente relata que: "pelo próprio tempo que os estudantes possuem, o ensino a distância exige mais de ti, estudante, é você quem tem que buscar o conhecimento a sua aprendizagem, gosto muito do meu curso e da modalidade a distância" (Estudante 4). Ainda de acordo com Moore e Kearsley (2012) para os estudantes de $\mathrm{EaD}$ devem haver razões específicas e claras para realização do curso o que, provavelmente, os torna discentes mais motivados e orientados a realização das atividades, uma vez que, em geral, são pessoas que buscam conhecimento nas suas áreas de atuação e procuram complementar o conhecimento prático que já possuem.

Tais aspectos vêm ao encontro da fala do respondente que afirma: "Estudo mais, procuro o que acho que falta no material ofertado pela instituição, o tempo sou eu que decido, é a minha vontade que prevalece" (Estudante 19). Outro respondente declara que: "O ato do acadêmico (a) impor-se para estudar mais (acredito que a 
EAD seja mais difícil por não ter encontros presenciais, o que faz com que o aluno se esforce mais e desta maneira, torne-se mais inteligente)" (Estudante 25). Havendo uma opinião complementar por parte de outro respondente ao afirmar que: "No meu ver, o ponto positivo do meu curso de graduação, é poder dar tudo de si, para com os trabalhos em grupos, saber que muito do que você está aprendendo, vem de uma educação que é tido em casa" (Estudante 27).

Uma visão interessante é a de um respondente ao relatar: "Concluí o ensino fundamental totalmente a distância e o médio parcialmente, isso facilitou a organização de meus estudos. Aprendi que um bom profissional se forma através de seus próprios esforços, independentemente da instituição" (Estudante 81).

\section{REFLEXÕES FINAIS}

A EaD está fundamentada em um diálogo didático mediado pelo professor/ tutor, independente do espaço, que auxilia e promove a aprendizagem independente. Porém todo e qualquer diálogo no âmbito da educação ocorre pelo desenvolvimento de práticas embasadas em sólidas bases teóricas, nesse sentido os estudantes pesquisados que apresentam como fator mais impactante para a qualidade do curso as discussões e as atividades realizadas, sendo estas resultantes de conteúdo e docência. Ao falar em promoção de discussões para aprendizagem e realização de atividades para a formação, não se pode excluir esses dois aspectos, pois o cerne donde são desenvolvidas essas ações é a educação.

Assim, salientamos que a Hipótese $\mathrm{H}_{1}$ sobre o indicador dedicação do estudante, foi parcialmente confirmada, pois a afirmação que o estudante ao se dedicar mais aos estudos, haveria por consequência maior probabilidade de o mesmo permanecer nos estudos. Neste sentido, o aspecto com maior impacto neste indicador é o aprofundamento de leituras, o que indica a consciência, do estudante de $\mathrm{EaD}$, de que estudar a distância também é um exercício de autonomia e proatividade. Sendo o segundo indicador a qualidade do curso, confirmado pela Hipótese $\mathrm{H}_{2}$ ao verificar que quanto melhor a qualidade do curso, maior a probabilidade de o estudante permanecer nos estudos. Tendo como aspectos principais a versarem sobre a qualidade do curso as atividades acadêmicas, os elementos multimídia como subsídio para apreensão dos conteúdos, a quantidade de atividades e as discussões promovidas durante o curso. Estando as hipóteses corroboradas pela análise qualitativa das questões abertas.

Acreditamos que esta investigação apresenta subsídios para analisar os fatores que levam a permanência de estudantes na Educação Superior independente da modalidade de ensino. Embora, o presente estudo, tenha sido realizado apenas na EaD é possível que os fatores verificados e validados possam ser aplicados a ambas as modalidades de ensino. 


\section{REFERÊNCIAS BIBLIOGRÁFICAS}

Almazán, O. M. (2015). Evaluación de la modalidad de interacción de la tutoría y los efectos en logro académico en entornos en línea. RIED. Revista Iberoamericana de Educación a Distancia, 18(1), 231.

Bardin, L. (2012). Análise de Conteúdo. Lisboa: Edições 70.

Cabrera, A. F., Nora, A., y Castañeda, M. B. (1992). The role of finances in the persistence process: A structural model. Research in Higher Education, 33(5), 571-593.

Cabrera, L., Bethencourt, J. T., Pérez, P. A., y Afonso, M. G. (2006). El problema del abandono de los estudios universitarios. Relieve, 12(2), 171-203.

Ethington, C. A. (1990). A psychological model of student persistence. Research in Higher Education, 31(3), 279-293.

Flick, U. (2013). Qualidade na pesquisa qualitativa. Porto Alegre: Artmed.

García Aretio, L. (2002). La educación a distancia: de la teoría a la práctica. Barcelona: Ariel.

García Aretio, L. (2014). Bases, mediaciones y futuro de la educación a distancia en la sociedad digital. Editorial Síntesis.

Hair, J. F., Black, W. C., Babin, B. J., Anderson, R. E., y Tatham, R. L. (2013). Análise multivariada de dados. Porto Alegre: Bookman Editora.

Himmel, E. (2002). Modelos de análisis de la deserción estudiantil en la educación superior. Revista calidad de la educación, 17, 91-108.

Lakatos, E. M., y Marconi, M. A. (2014). Metodologia do Trabalho Científico: Procedimentos Básicos, Pesquisa Bibliográfica, Projeto e Relatório, Publicações e Trabalhos Científicos. São Paulo: Atlas.

Litto, F. M., y Formiga, M. (2012). Educação a distância: o estado da arte. São Paulo: Pearson.
Malhotra, N. K. (2012). Pesquisa de marketing: uma orientação aplicada. Porto Alegre: Bookman Editora.

Martinez, M. (2003). High attrition rates in e-learning: challenges, predictors, and solutions. The Elearning Developers' Journal, 14. Recuperado de http://www.elearningguild.com pdf/2/071403MGT-L.pdf

Moncada Mora, L. F. (2014). La integración académica delosestudiantes universitarios como factor determinante del abandono de corto plazo. Un análisis en el Sistema de Educación Superior a Distancia del Ecuador. RIED. Revista Iberoamericana de Educación a Distancia, 17(2), 173-196.

Moore, M., Kearsley, G. (2012). Educação a Distância: Uma visa integrada. São Paulo: Cengage Learning.

Palloff, R. M., y Pratt, K. (2004). O aluno virtual. Porto Alegre: Artmed.

Pascarella, E. T. (1985). Students' affective development within the college environment. The Journal of Higher Education, 56(6), 640-663.

Ristoff, D. (1999). Universidade em foco: reflexões sobre a educação superior. Florianópolis: Insular.

Ristoff, D. (2012). A trajetória dos cursos de graduação a distância. Associação Brasileira de Educação a Distância $A B E D$. Recuperado de http://www.abed. org.br/congresso2012/programa.asp

Spady, W. G. (1971). Dropouts from higher education: Toward an empirical model. Interchange, 2(3), 38-62.

Tinto, V. (1997). Classrooms as communities: Exploring the educational character of student persistence. Journal of higher education, 68(6), 599-623.

Tinto, V. (2012). Completing College: rethinking institutional action. London: Chicago Press.

Tinto, V., y Pusser, B. (2006). Moving from theory to action: Building a model of 
institutional action for student success. National Postsecondary Education Cooperative, 1-51. Recuperado de http:// web.ewu.edu/groups/academicaffairs/ IR/NPEC 5 Tinto Pusser Report.pdt

\section{PERFIL ACADÊMICO E PROFESIONAL DOS AUTORES}

Pricila Kohls dos Santos. Pós-doutoranda no Centro de Estudos em Educação Superior - PUCRS. Doutora em Educação pela PPGEDU/PUCRS, com estágio sanduíche na Universidad Politécnica de Madrid (2014). Participante do Projeto Alfa GUIA (Gestão Universitária Integral do Abandono). Mestre em Educação pelo PPGEDU/PUCRS, possui graduação em Pedagogia Multimeios e Informática Educativa pela Pontifícia Universidade Católica do Rio Grande do Sul.

E-mail: pricilas@terra.com.br

Lucia Maria Martins Giraffa. Pós-Doutorado na Universidade do Texas (Austin) no College of Education, Bolsista CAPES, Doutorado em Ciências da Computação pela Universidade Federal do Rio Grande do Sul, Mestrado em Educação pela Pontifícia Universidade Católica do Rio Grande do Sul, Especialização em Análise de Sistemas pela Pontifícia Universidade Católica do Rio Grande do Sul, graduação em Licenciatura Curta Em Ciências pela Universidade Federal do Rio Grande do Sul.

E-mail: giraffa@pucrs.br

\section{ENDEREÇO DOS AUTORES}

PUCRS - Pontifícia Universidade Católica do Rio Grande do Sul

Av. Ipiranga, 6681 - Partenon - Porto Alegre

RS - Brasil

Data de recebimento do artigo: 24/06/2016

Data de aceitação do artigo: 07/09/2016

\section{Como citar esse artigo:}

Kohls dos Santos, P., Martins Giraffa, L. M. (2017). Permanência na Educação Superior a distância. RIED. Revista Iberoamericana de Educación a Distancia, 2o(1), pp. 305-321. doi: http://dx.doi.org/10.5944/ried.20.1.16808 